\title{
Diagnosis of pulmonary complications of the acquired immune deficiency syndrome
}

\author{
MARK J ROSEN, TONY WY TOW, ALVIN S TEIRSTEIN, MING T CHUANG, \\ ALBERTO MARCHEVSKY, EDWARD J BOTTONE
}

From the Departments of Medicine, Pathology, and Microbiology, Mount Sinai Medical Center, New York

ABSTRACT Forty eight patients with the acquired immunedeficiency syndrome (AIDS) presented to the Mount Sinai Hospital in New York with persistent cough and dyspnoea or an abnormal chest radiograph, or both. Thirty two (67\%) were found to have Pneumocystis carinii pneumonia, either alone or in combination with another pathogen. Of these patients, eight $(25 \%)$ had a normal chest radiograph. Abnormalities in the single breath carbon monoxide diffusing capacity and alveolar-arterial oxygen gradient $\left((\mathrm{A}-\mathrm{a}) \mathrm{DO}_{2}\right)$ suggested infection with Pneumocystis carinii . Fibreoptic bronchoscopy with transbronchial biopsy was $100 \%$ sensitive in the diagnosis of pneumocytis pneumonia. Fibreoptic bronchoscopy should be undertaken in patients suspected of having a pulmonary complication of AIDS, even if the chest radiograph is normal.

The acquired immune deficiency syndrome (AIDS) is characterised by an unusually aggressive form of Kaposi's sarcoma, Pneumocystis carinii pneumonia, or other life threatening opportunistic infection in patients who are under the age of 60 and who have no previous history of either illness or treatment causing immunosuppression..$^{1-7}$ In addition, cases of lymphocytic interstitial pneumonia ${ }^{8}$ and malignant lymphoma ${ }^{9-11}$ have been reported in patients with AIDS. The great majority of over 3000 patients with AIDS reported to the Centers for Disease Control in the United States are male homosexuals, but the disorder has also been encountered in intravenous drug abusers, ${ }^{42-14}$ Haitian immigrants, ${ }^{15}{ }^{16}$ and patients with haemophilia A. .7-20 $^{-20}$

Mortality among patients with AIDS is high, most patients succumbing to opportunistic pulmonary infections. ${ }^{42122}$ In addition to pneumocystis pneumonia, patients with AIDS have developed pulmonary infections caused by Mycobacterium avium intracellulare, Mycobacterium tuberculosis, Cryptococcus neoformans, Candida albicans, cytomegalovirus, and herpes simplex virus. ${ }^{1321}$ Patients are frequently diagnosed as having AIDS because they are found to have pneumocystis pneumonia or infection with another opportunistic

Address for reprint requests: Mark J Rosen, Annenberg 24-30, Mount Sinai Medical Center, 1 Gustave L Levy Place, New York, 10029, USA.

Accepted 21 May 1985 pulmonary pathogen. Possibly early detection and treatment of these infections could improve survival. There is still, however, no general agreement on the best diagnostic approach to these patients. In this paper we present the results of diagnostic studies in patients with suspected pulmonary complications of AIDS, and emphasise the value of fibreoptic bronchoscopy in establishing the diagnosis.

\section{Methods}

From December 1981 to December 1983, 64 patients who were at high risk of developing AIDS came to our attention because of persistent cough, dyspnoea, or an abnormal chest radiograph. On the basis of the criteria proposed by the United States Centers for Disease Control, ${ }^{21} 45$ of these patients were shown to have AIDS because of the finding of Kaposi's sarcoma or opportunistic infection. Three additional patients at risk of AIDS were found to have a lymphoproliferative disorder, and are included in this study. The remaining 16 patients proved to have other pulmonary infections not consistent with the diagnosis of AIDS.

Arterial blood gas determinations, spirometric tests, and the single breath test of carbon monoxide diffusing capacity were performed whenever possible. All patients underwent fibreoptic bronchoscopy under local anaesthesia. Brush biopsy specimens were sent for cytological study, Gram staining, and in seven cases Giemsa staining. Transbronchial 
forceps biopsy specimens were obtained in all but one patient; touch prints were made of biopsy material for Giemsa staining. Lung tissue was evaluated by haematoxylin and eosin, methenamine silver, and Ziehl-Neelsen staining.

A diagnosis of pneumocystis pneumonia was made if the organisms were identified in brush biopsy specimens, touch imprints made from tissue specimens or glass slides, or lung tissue. Methenamine silver stain was used to identify cyst forms, and Giemsa staining identified trophozoites. Cytomegalovirus infection was diagnosed by the characteristic histological findings in biopsy specimens. Other infections were diagnosed by the use of culture techniques.

Measures designed to avoid spread of infection were based on avoiding contact with saliva, respiratory tract secretions, and blood. ${ }^{23}$ Disposable mouthpieces were used for pulmonary function tests, and the equipment was thoroughly cleaned after each use. Persons performing fibreoptic bronchoscopy wore gowns, gloves, masks, and protective eyeware, and the bronchoscope was carefully cleaned and gas sterilised after each procedure. Specimens of tissue, blood, and secretions were transported in clearly labelled sealed plastic bags.

\section{Results}

Of the 48 patients in this study, 34 men were homosexual or bisexual, seven men and three women were intravenous drug abusers, two men were both homosexual and users of intravenous drugs, one man had haemophilia $A$, and one man had no apparent risk factors. The mean age at the time of presentation was 35 years, with a range of 24 to 49 years.

\section{CHEST RADIOGRAPHY}

In 24 of the 32 patients found to have pneumocystis pneumonia, the chest radiograph showed bilateral diffuse interstitial infiltrations, usually of the reticulonodular pattern. Importantly, eight of the 32 with pneumocystis pneumonia had normal chest radiographs as reported by the hospital radiologists and after subsequent review. Fibreoptic bronchoscopy was performed in these eight patients because of complaints of dyspnoea and cough and the finding of a decreased TLCO or increased (A-a) $\mathrm{DO}_{2}$, or both, despite the negative chest radiograph.

\section{PULMONARY FUNCTION TESTS}

Pulmonary function tests were performed in eight cases before fibreoptic bronchoscopy. None of these patients had a history of lung disease before developing AIDS. The total lung capacity was reduced in one ( $<80 \%$ predicted). Five had a decreased forced expiratory volume in one second ( $<80 \%$ predicted) and decreased forced vital capacity. TLCO was reduced ( $<60 \%$ predicted) in all seven patients tested.

\section{ARTERIAL BLOOD GAS TENSIONS}

Twenty seven patients had arterial blood gas determinations before fibreoptic bronchoscopy. In 21 $(78 \%)$, the partial pressure of oxygen $\left(\mathrm{PaO}_{2}\right)$ was less than $80 \mathrm{~mm} \mathrm{Hg}(10.7 \mathrm{kPa})$. In 26 of the 27 $(96 \%)$ the (A-a) $\mathrm{Do}_{2}$ was greater than $20 \mathrm{~mm} \mathrm{Hg}$ $(2.7 \mathrm{kPa})$.

\section{FIBREOPTIC BRONCHOSCOPY}

All 48 patients underwent fibreoptic bronchoscopy during the initial evaluation of suspected opportunistic infection complicating AIDS. The results of bronchoscopy are presented in table 1 . The most common pathogen was Pneumocystis carinii, which was found either alone or in combination with another pathogen in 32 cases $(67 \%)$,

The techniques used in establishing the diagnosis of pneumocystis pneumonia in patients with AIDS are set out in table 2. Histological examination of biopsy specimens using silver methenamine stain was the most sensitive indicator of pneumocystis pneumonia in our series, being positive in all 32 patients in whom biopsy was performed. Giemsa stained biopsy touch prints were positive in $28 / 30$ cases $(93 \%)$. When Giemsa stained preparations of bronchial brushings and washings were studied, they were found to be positive in five of seven cases (71\%) each. In several cases empirical treatment with trimethoprim and sulfamethoxazole had been started up to three days before the bronchoscopy was performed without apparent reduction in diagnostic yield.

Cytomegalovirus was recognised by the presence of characteristic intranuclear and intracytoplasmic inclusions in biopsy specimens. This infection was found in three patients $(6 \%)$, one of whom also had pneumocystis pneumonia.

Cultures of bronchial washings disclosed nontuberculous mycobacteria in two patients $(4 \%)$. Staphylococcus aureus was isolated in bronchial washings in three patients $(6 \%)$ and Haemophilus infuenzae and Histoplasma capsulatum each occurred in one patient $(2 \%)$.

One patient with widespread cutaneous Kaposi's sarcoma and bilateral pleural effusions had a nondiagnostic pleural biopsy, but fibreoptic bronchoscopy and colonoscopy both showed intraluminal lesions typical of Kaposi's sarcoma.

A lymphoproliferative disorder affecting the pulmonary parenchyma was diagnosed by transbron- 
Table 1 Diagnosis established with fibreoptic bronchoscopy in 48 patients with AIDS

\begin{tabular}{lc}
\hline & No (\%) \\
\hline Pneumocystis pneunomia & $30(63)$ \\
Pneumocystis pneumonia with Haemophilus & $1(2)$ \\
infuenzae & $1(2)$ \\
Pneumocystis pneumonia with cytomegalovirus & $2(4)$ \\
Cytomegalovirus & $1(2)$ \\
Mycobacterium avium intracellulare & $1(2)$ \\
M kansasii & $3(6)$ \\
Staphylococcus aureus & $1(2)$ \\
Histoplasma capsulatum & $1(2)$ \\
Kaposi's sarcoma & $1(2)$ \\
Lymphocytic interstitial pneumonitis & $1(2)$ \\
Lymphoma & $5(10)$ \\
No specific diagnosis & $48(99)$ \\
\hline
\end{tabular}

*The total of $99 \%$ is due to rounding of individual percentages.

chial biopsy in two patients. One had lymphocytic interstitial pneumonitis and the other immunoblastic lymphoma. Bronchoscopy was not diagnostic in the remaining five patients $(10 \%)$.

Most patients tolerated bronchoscopy well. Two patients, however, developed pneumothoraces requiring thoracostomy tube drainage after transbronchial biopsy. One of these patients was successfully treated but the other had a persistent bronchopleural fistula until he died of staphylococcal sepsis. One patient with haemophilia $\mathrm{A}$ had haemoptysis (50 $\mathrm{ml}$ of blood) after a bronchial brush biopsy.
Bleeding subsided spontaneously and forceps biopsy was not carried out.

\section{OPEN LUNG BIOPSY}

Two patients who had no specific diagnosis after fibreoptic bronchoscopy underwent open lung biopsy. Pulmonary infiltration with Kaposi's sarcoma was diagnosed in one; but in the other patient open lung biopsy did not lead to a diagnosis. A third patient, with lymphocytic interstitial pneumonitis diagnosed by bronchoscopy, also had an open lung biopsy, which confirmed this diagnosis.

\section{NECROPSY}

Thirteen patients had complete necropsies; the pulmonary findings are listed in table 3 . No case of pneumocystis pneumonia was discovered at the time of necropsy that had not been diagnosed during life. Two cases of cytomegalovirus infection, two cases of Kaposi's sarcoma, and one case of immunoblastic lymphoma affecting the lungs were, however, discovered only at necropsy. One patient with a premortem diagnosis of disseminated infection with acid fast bacilli died before identification of the organism was possible. He was treated with isoniazid and rifampicin. Both $M$ tuberculosis and $M$ avium intracellulare were cultured from the lungs at the time of postmortem examination.

Table 2 Yield from fibreoptic bronchoscopy in 32 patients with AIDS and Pneumocystis carinii pneumonia

\begin{tabular}{|c|c|c|}
\hline Technique & $\begin{array}{l}\text { No of positive/total } \\
\text { procedures }\end{array}$ & $\%$ positive \\
\hline $\begin{array}{l}\text { Transbronchial biopsy } \\
\text { Touch preparation } \\
\text { Bronchial brush } \\
\text { Bronchial wash }\end{array}$ & $\begin{array}{c}32 / 32 \\
28 / 30 \\
5 / 7 \\
5 / 7\end{array}$ & $\begin{array}{r}100 \\
93 \\
71 \\
71\end{array}$ \\
\hline
\end{tabular}

Table 3 Results of necropsy in 13 patients with pulmonary complications of AIDS

\begin{tabular}{|c|c|c|}
\hline Patient No & Clinical diagnosis & Pulmonary necropsy diagnosis \\
\hline $\left.\begin{array}{l}1 \\
2 \\
3 \\
4\end{array}\right\}$ & Pneumocystis pneumonia & Pneumocystis pneumonia \\
\hline 5 & $\begin{array}{l}\text { Resolved pneumocystis pneumonia, } \\
\text { central nervous system lymphoma }\end{array}$ & $\begin{array}{l}\text { Cytomegalovirus, central nervous } \\
\text { system lymphoma }\end{array}$ \\
\hline 6 & Staphylococcal pneumonia & Staphylococcal pneumonia \\
\hline 7 & $\begin{array}{l}\text { Resolved pneumocystis pneumonia, bacterial } \\
\text { pneumonia }\end{array}$ & $\begin{array}{l}\text { Adult respiratory distress syndrome, } \\
\text { disseminated Aspergillus and Candida }\end{array}$ \\
\hline 8 & Disseminated acid fast bacillary infection & $\begin{array}{l}M \text { tuberculosis and avium } \\
\text { intracellulare (postmortem cultures) }\end{array}$ \\
\hline 9 & Staphylococcal pneumonia & $\begin{array}{l}\text { Staphylococcal pneumonia, } \\
\text { Kaposi's sarcoma }\end{array}$ \\
\hline 10 & Mycobacterium avium intracellulare & $\begin{array}{l}M \text { avium intracellulare, } \\
\text { Kaposi's sarcoma }\end{array}$ \\
\hline $\begin{array}{l}11 \\
12\end{array}$ & $\begin{array}{l}\text { Pneumocystis pneumonia } \\
\text { Immunoblastic lymphoma }\end{array}$ & $\begin{array}{l}\text { Pneumocystis pneumonia, cytomegalovirus } \\
\text { Immunoblastic lymphoma }\end{array}$ \\
\hline 13 & $M$ kansasii, pneumocystis pneumonia & $\begin{array}{l}\text { Immunoblastic lymphoma; no evidence } \\
\text { of active } M \text { kansasii or } \\
\text { pneumocystis infection }\end{array}$ \\
\hline
\end{tabular}




\section{Discussion}

By far the most common pulmonary complication of AIDS was pneumocytis pneumonia, occurring alone or in combination with another infection in 32 of the 48 patients $(67 \%)$ during the initial evaluation.

The chest radiograph showed bilateral diffuse interstitial densities in most of the patients with pneumocystis pneumonia, although eight patients with proved pneumocystis pneumonia had normal chest radiographs. Most patients were too ill to undergo pulmonary function tests, but when they were performed a diffusing capacity of less than $60 \%$ was found, confirming that this is a sensitive indicator of pneumocystis pneumonia. Arterial blood gas determinations were also sensitive indicators of pneumocystis infection.

Several other diagnoses besides pneumocystis pneumonia were established by means of fibreoptic bronchoscopy, including infection with cytomegalovirus, $M$ avium intracellulare, $M$ kansasii, Staphylococcus aureus, Haemophilus inftuenzae, and Histoplasma capsulatum. Pulmonary Kaposi's sarcoma, immunoblastic lymphoma, and lymphocytic interstitial pneumonitis were also diagnosed by fibreoptic bronchoscopy. But, in contrast to its high sensitivity in diagnosing opportunistic infections in patients with AIDS, fibreoptic bronchoscopy played little part in demonstrating Kaposi's sarcoma in the lungs.

There is no general agreement on the best technique for establishing the diagnosis of diffuse lung disease in immunocompromised patients. While some centres prefer to obtain lung brushings, biopsy specimens, and lavage fluid through the fibreoptic bronchoscope as the first diagnostic procedure, ${ }^{24}$ other authorities prefer to proceed directly to open lung biopsy, citing its higher diagnostic yield. ${ }^{25} 26$ This uncertainty is reflected in case reports of patients with AIDS with diffuse lung disease, where both fibreoptic bronchoscopy and open lung biopsy have been used in the diagnosis of opportunistic infections. ${ }^{4122728}$ In our series AIDS was either previously diagnosed or suspected in all cases, and they underwent fibreoptic bronchoscopy because of a suspected opportunistic pulmonary infection. A specific diagnosis was established by bronchoscopy in 43 patients $(90 \%)$.

In this series the sensitivity of transbronchial biopsy in the diagnosis of pneumocystis pneumonia was $100 \%$. This is in general agreement with the findings of Coleman and coworkers, ${ }^{29}$ who found transbronchial biopsy to be $79 \%$ sensitive in diagnosing pneumocystis pneumonia in patients with AIDS. Giemsa stains of touch preparations were positive for pneumocystis pneumonia in $28 / 30$ cases
(93\%), and because of the rapidity of the staining procedure they had the advantage of enabling the diagnosis to be made within hours of the bronchoscopy. Giemsa stains of bronchial brushings and washings were positive in $5 / 7$ cases $(71 \%)$. It is noteworthy that no diagnosis of pneumocystis pneumonia was made from any of three open lung biopsies and 13 necropsies that had not already been established by fibreoptic bronchoscopy.

We conclude that when a patient is suspected of having a pulmonary complication of AIDS an early and determined attempt to reach a diagnosis is in order, even when the chest radiograph is normal. Measurement of diffusing capacity and arterial blood gas tensions provide useful information during the initial evaluation, as both are highly sensitive indicators of the presence of pneumocystis pneumonia. If the result of either of these tests or the chest radiograph is abnormal, the patient should undergo fibreoptic bronchoscopy with transbronchial biopsy, touch preparation of biopsy specimens, and bronchial brushings and washings. In addition to routine histopathological studies, special staining for pneumocystis pneumonia and acid fast bacilli should be performed. Specimens should also be cultured for bacterial pathogens, mycobacteria, and fungi.

Bronchoalveolar lavage has been proposed as a useful technique in the diagnosis of opportunistic infection in patients with AIDS. ${ }^{30}$ Although we did not perform this procedure in any of our patients, we agree that this technique is potentially useful, particularly in patients with bleeding disorders or requiring mechanical ventilation, in whom transbronchial biopsy may be contraindicated because of the high risk of uncontrolled bleeding or tension pneumothorax.

Fibreoptic bronchoscopy should be the first invasive procedure in establishing the diagnosis of a pulmonary complication of AIDS. The procedure is safe, well tolerated by the patients, and highly sensitive, particularly in the diagnosis of pneumocystis pneumonia. Open lung biopsy should be reserved for those patients in whom fibreoptic bronchoscopy is non-diagnostic.

This work was supported by the Catherine and Henry Gaisman Foundation. We would like to thank Ms Sarah Lyon for her expert assistance in the preparation of this manuscript.

\section{References}

1 Gottlieb MS, Schanker HM, Fan PT, et al. Pneumocystis pneumonia: Los Angeles. Morbid Mortal Weekly Rep 1981;30:250-2. 
2 Friedman-Kien A, Lanbenstein L, Marmor M, et al. Kaposi's sarcoma and Pneumocystis pneumonia among homosexual men: New York City and California. Morbid Mortal Weekly Rep 1981;30:305-8.

3 Gottlieb MS, Schroff RS, Schanker HM, et al. Pneumocystis carinii pneumonia and mucosal candidiasis in previously healthy homosexual men: evidence of a new acquired cellular immunodeficiency. $N$ Engl J Med 1981;305:1425-31.

4 Masur H, Micheles MA, Greene JB, et al. An outbreak of community-acquired Pneumocystis carinii pneumonia: initial manifestation of cellular immune dysfunction. $N$ Engl J Med 1981;305:1431-8.

5 Siegal FP, Lopez C, Hammer GS, et al. Severe acquired immunodeficiency in male homosexuals, manifested by chronic perianal herpex simplex lesions. $N$ Engl J Med 1981;305:1439-44.

6 Hymes KB, Cheung T, Greene JB, et al. Kaposi's sarcoma in homosexual men: a report of eight cases. Lancet 1981;ii:598-600.

7 Urmacher C, Myskowski P, Ochoa M, et al. Outbreak of Kaposi's sarcoma with cytomegalovirus infection in young homosexual men. Am J Med 1982;72:569-75.

8 Saldana MJ, Mones J, Buck BE. Lymphoid interstitial pneumonia in Haitian residents of Florida. Chest 1983;84:347 (abstract).

9 Ziegler JL, Drew WL, Miner RC, et al. Outbreak of Burkitt's-like lymphoma in homosexual men. Lancet 1982;ii:631-3.

10 Ciobanu N, Andreeff M, Safai B, et al. Lymphoblastic neoplasia in a homosexual patient with Kaposi's sarcoma. Ann Intern Med 1983;98:151-5.

11 Levine AM, Meyer PR, Begandy MK, et al. Development of B-cell lymphoma in homosexual men: clinical and immunologic findings. Ann Intern med 1984; 100: 7-13.

12 Masur H, Michelis MA, Wormser GP, et al. Opportunistic infection in previously healthy women. Initial manifestations of a community-acquired cellular immunodeficiency. Ann Intern Med 1982;97:533-9.

13 Greene JB, Sidhu GS, Lewin, et al. Mycobacterium avium-intracellulare. A cause of disseminated lifethreatening infection in homosexuals and drug abusers. Ann Intern Med 1982;97:539-46.

14 Wormser GP, Krupp LB, Hanahan JP, et al. Acquired immunodeficiency syndrome in male prisoners: new insights into an emerging syndrome. Ann Intern Med 1983;98: 297-303.

15 Viera J, Frank E, Spira TJ, et al. Acquired immune deficiency in Haitians: opportunistic infections in previously healthy Haitian immigrants. $N$ Engl J Med 1983;308: 125-9.
16 Pitchenik AE, Fischl MA, Dickenson GM, et al. Opportunistic infections and Kaposi's sarcoma among Haitians: evidence of a new acquired immunodeficiency state. Ann Intern Med 1983;98:277-84.

17 Anonymous. Pneumocystis carinii pneumonia among persons with hemophilia A. Morbid Mortal Weekly Rep 1982;31:365-7.

18 Davis KC, Horsburgh CR, Hasiba U, et al. Acquired immunodeficiency syndrome in a patient with hemophilia. Ann Intern Med 1983;98:284-6.

19 Poon M-C, Landay A, Prasthofer EF, et al. Acquired immunodeficiency syndrome with Mycobacterium avium-intracellulare infection in a previously healthy patient with classic hemophilia: clinical, immunologic and virologic findings. Ann Intern Med 1983;98:28790.

20 Elliot JL, Hoppes WL, Platt MS, et al. The acquired immunodeficiency syndrome and Mycobacterium avium-intracellulare bacteremia in a patient with hemophilia. Ann Intern Med 1983;98:290-3.

21 Mildvan D, Mathur U, Enlow RW, et al. Opportunistic infections and immune deficiency in homosexual men. Ann Intern Med 1982;96:700-4.

22 Follansbee SE, Busch DF, Wofsy CB. An outbreak of Pneumocystis carinii pneumonia in homosexual men. Ann Intern Med 1982;96:705-13.

23 Hopewell PC, Luce JM. Pulmonary involvement in the acquired immunodeficiency syndrome. Chest 1985; 87:104-12.

24 Matthay RA, Moritz ED. Invasive procedures for diagnosing pulmonary infection: a critical review. Clin Chest Med 1981;2:3-18.

25 Graeve AH, Saul VA, Aki BF. Role of different methods of lung biopsy in the diagnosis of lung lesions. Am J Surg 1980;140:742-6.

26 Hasleton PS, Curry A. Pneumocystis carinii: the continuing enigma. Thorax 1982;37:481-5.

27 Spagenthal S, Beer DJ, Snydman DR. Pneumocystis carinii and cytomegalovirus pneumonia in a previously healthy adult. Am Rev Respir Dis 1982;125:601-3.

28 Waldhorn RE, Tsou E, Kerwin DM. Pneumocystis carinii pneumonia in a previously healthy adult. JAMA 1982;247:1860-1.

29 Coleman DL, Dodek PM, Luce JM, et al. Diagnostic utility of fiberoptic bronchoscopy in patients with Pneumocystis carinii pneumonia and the acquired immune deficiency syndrome. Am Rev Respir Dis 1983; 128: 795-9.

30 Dake M, Wong H, Golden J, et al. Diagnosis of pulmonary infections by bronchoalveolar lavage in patients with acquired immunodeficiency syndrome (AIDS). Chest 1983;84:347 (abstract). 